Special issue of the 2nd International Conference on Computational and Experimental Science and Engineering (ICCESEN 2015)

\title{
Synthetic Unit Hydrograph of Small Catchments by Using GIS
}

\author{
A.Y. GÜNAL* AND A. GÜVEN \\ Gaziantep University, Civil Engineering Department, Gaziantep, Turkey
}

\begin{abstract}
In this study, synthetic unit hydrograph parameters which are $q_{p}, t_{p}, t_{b}$ are calculated by using Synder, Mockus, SCS (Soil Conservation Service) and DSI (State Hydraulic Works) methods. First according to observed data, calculations were done. Then the mentioned above methods, which are based on both topographic map and geographic information systems values, were applied. Three catchments, Damlica, Vize, Kumdere were studied. Synder, Mockus, SCS and DSI methods were applied for each catchment.
\end{abstract}

DOI: 10.12693/APhysPolA.130.130

PACS/topics: 92.40.-t, 92.10.Yb

\section{Introduction}

Mathematical models are widely used in the engineering problems to reflect what exists in the reality and give solutions by using advanced computer technology. Because of this, modeling is the most powerful tool for solving engineering problems. Hydrological models give more realistic solutions due to the latest development in technology. A general overview of the hydrologic models was done in $[1,2]$. Hydrological models are very beneficial, however in reality most of the hydrological models have many parameters and those parameters must be adjusted for good simulation.

In this study Damlica, Vize, and Kumdere catchments, were studied. To determine design discharges of hydraulic structures, it is necessary to determine unit hydrographs for the corresponding catchments. In Turkey, suitable data to determine the unit hydrograph of catchments are not easy to find, therefore unit hydrographs are usually determined synthetically. The unit hydrograph theory was first introduced by Sherman in 1932 . In this study, synthetic unit hydrographs were obtained for catchments where rainfall-runoff data were also available to determine actual unit hydrographs. The goals of the study were, first, to compare the unit hydrographs obtained synthetically and from observed rainfall-runoff data. Second, by using GIS techniques to obtain the synthetic unit hydrographs and show their effectiveness. To satisfy the second goal, SCS, Synder, Mockus and DSI synthetic unit hydrograph determination methods were chosen, since these methods were very suitable for the application of GIS techniques.

\section{Studied area and data collection}

The studied areas are located in the Marmara catchment in Turkey. Marmara catchment is in the North

\footnotetext{
*corresponding author; e-mail: agunal@gantep.edu.tr
}

West of Turkey. The selected catchments were Damlica, Vize, Kumdere. These catchments are shown in Fig. 1.

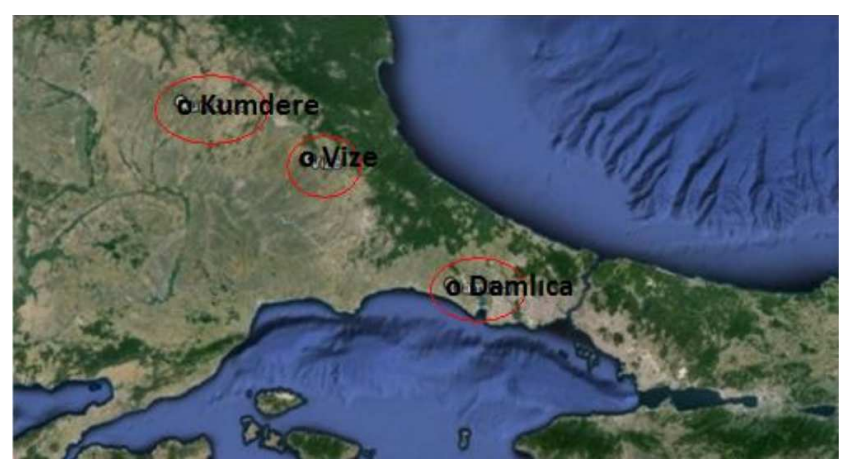

Fig. 1. Damlica, Vize and Kumdere catchments.

\subsection{Damlica catchment}

Damlica catchment is located on the Çatalca and Kumburgaz highway. The Damlica catchment is $9 \mathrm{~km}$ to Kumburgaz and $51 \mathrm{~km}$ to Istanbul. The topographic map of the Damlica catchment is given in Fig. 2. The area of the catchment determined from the topographic map is $8.26 \mathrm{~km}^{2}$. The area of Damlica catchment was also calculated using GIS technique, which gave a value of $7.63 \mathrm{~km}^{2}$.

\subsection{Kumdere catchment}

Kumdere catchment is located on the northwest of Edirne province. The Kumdere catchment is $10 \mathrm{~km}$ to Edirne city centre. Area of the catchment is $4.40 \mathrm{~km}^{2}$ according to topographic map. The topographic map of the Kumdere catchment is given in Fig. 3.

\subsection{Vize catchment}

Vize catchment is located at the south of Vize county of Kırklareli province. The Vize catchment is located at the boundary of Topçu village and at $11 \mathrm{~km}$ to Vize village. Area of the catchment is $4.64 \mathrm{~km}^{2}$ according to topographic map. The topographic map of the Vize catchment is given in Fig. 4. 


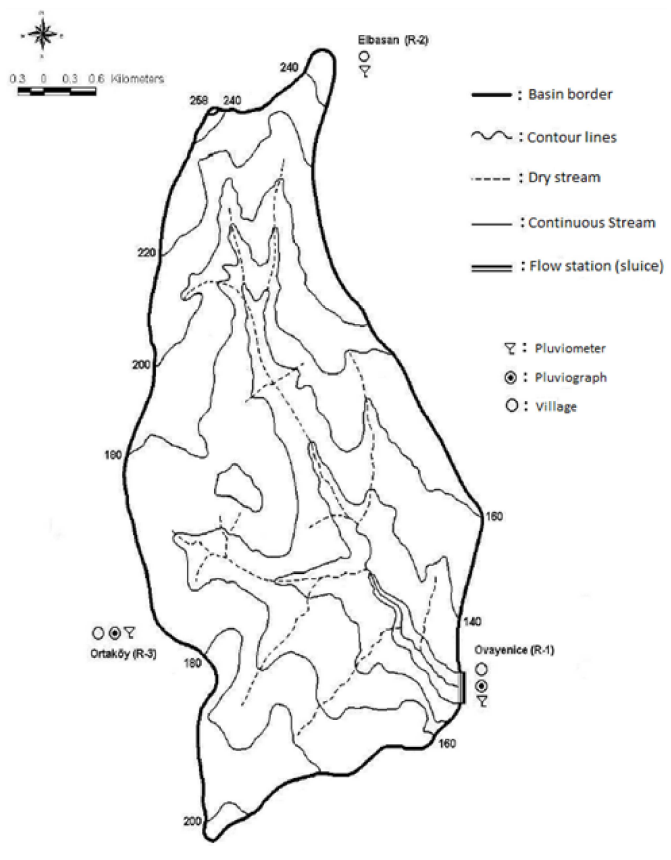

Fig. 2. Damlica catchment.

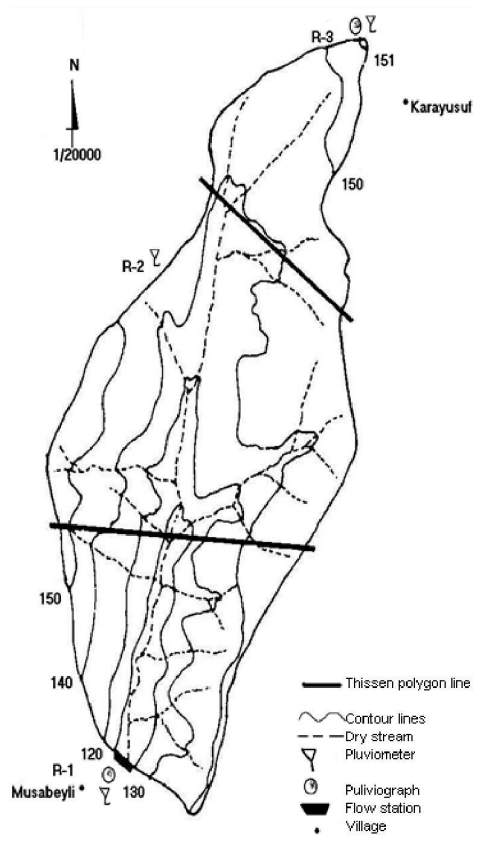

Fig. 3. Kumdere catchment.

\section{Methodology}

\subsection{Unit hydrograph}

Hydrograph is a graph that represents the stream discharge versus time. Flow hydrograph is the result of the runoff, which consists of the overland flow, interflow and base flow which are generated from rainfall. The unit hydrograph is the direct runoff hydrograph produced by a storm of given duration, such that the total volume of excess rainfall is $1 \mathrm{~mm}$. The total volume of direct runoff is also $1 \mathrm{~mm}[3,4]$.

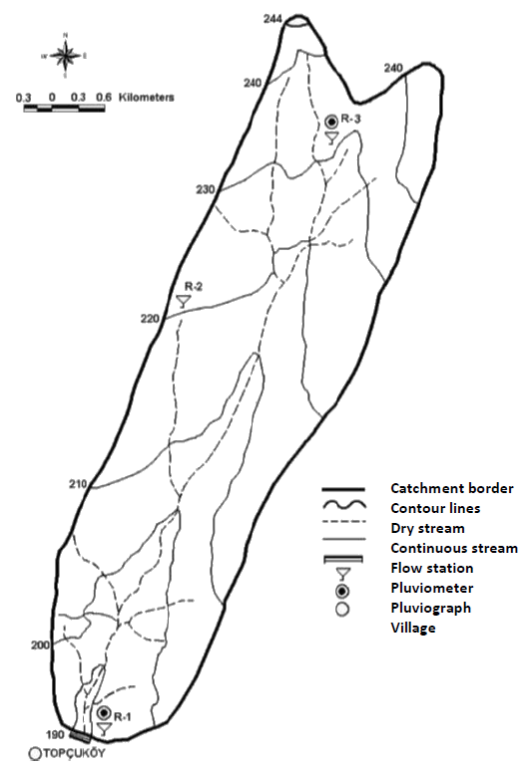

Fig. 4. Vize catchment.

\subsubsection{Snyder's unit hydrograph}

One of the methods to obtain synthetic unit hydrograph was given by Snyder, who selected three parameters, namely hydrograph base time $t_{b}$, peak discharge $q_{p}$ and catchment lag $t_{p}$, as the parameters to define the unit hydrograph.

\subsubsection{Mockus unit hydrograph}

Because of simplicity in calculations and drawing triangular unit hydrograph Mockus method is often preferred. It is applied without gauging station on the river.

\subsubsection{SCS unit hydrograph}

SCS unit hydrograph is the dimensionless unit hydrograph developed by the Soil Conservation Service in 1972 [3]. The SCS dimensionless unit hydrograph is a synthetic unit hydrograph in which the discharge is expressed as a ratio of discharge $q$ to peak discharge $q_{p}$ and the time by the ratio of time $t$ to time to peak of the unit hydrograph $t_{p}$.

3.1.4. Turkish state of hydraulic works (DSI) unit hydrograph

DSI hydrograph is a graph showing the temporal change in the flow cross section in a stream. Synthetic unit hydrograph allows the calculation of the flood based on the value that can originate from long-term observations which are not reliable.

\section{Results and discussion}

\subsection{Comparison of observed and synthetic methods for catchments}

Comparison of $\mathrm{UH}_{60}$ graphs by using observed values and values obtained using synthetic methods are given for each catchment (Damlica, Vize, Kumdere) studied in this work. Comparison of $\mathrm{UH}_{60}$ for Damlica, obtained using topographic map values and GIS values is given in Fig. 5. 

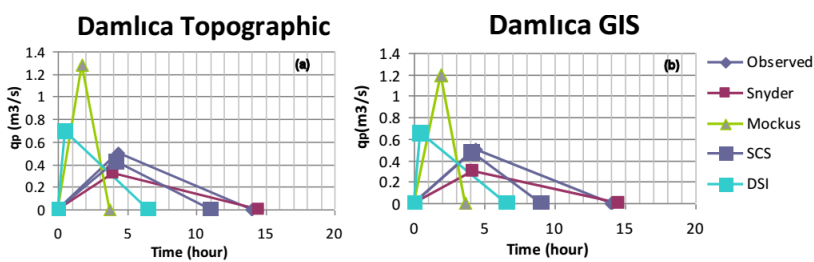

Fig. 5. Comparisons of unit hydrographs obtained using (a) topographic map and (b) GIS for Damlica catchment.

\subsubsection{Damlica catchment}

Figure 5 shows that peak discharge $q_{p}$ values in Snyder and Mockus methods are overestimated and this value is underestimated in SCS and DSI methods based on topographic map. Base time $t_{b}$ value is overestimated in Snyder method and underestimated in Mockus, SCS and DSI methods, which are based on using of topographic map and GIS.

\subsubsection{Vize catchment}

Figure 6 shows that peak discharge $q_{p}$ values in Snyder methods are predicted correctly are underestimated in Mockus, SCS and DSI methods, which use the topographic map. Base time $t_{b}$ value is underestimated in all applied (Snyder, Mockus, SCS and DSI) methods, which use the topographic map.
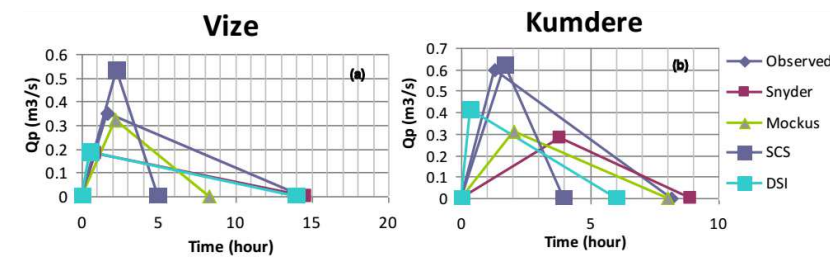

Fig. 6. Comparisons of unit hydrographs obtained using topographic map for (a) Vize and (b) Kumdere catchments.

\subsubsection{Kumdere catchment}

Figure 6 also shows that peak discharge $q_{p}$ values in Snyder and SCS methods are overestimated and are underestimated in Mockus and DSI methods based on using of the topographic map. Base time $t_{b}$ values are overestimated in all applied (Snyder, Mockus, SCS and DSI) methods, base on topographic map.

\section{Conclusions}

Peak discharge, $q_{p}$ values in Snyder method are underestimated for all catchments. Base time, $t_{b}$ values in Snyder method are overestimated for all catchments. Peak discharge, $q_{p}$ values in Mockus method are underestimated for Vize and Kumdere catchment and overestimated for Damlica catchment because of the shape factor of these catchments. Base time, $t_{b}$ values in Mockus method are underestimated for all catchments. Peak discharge, $q_{p}$ values in SCS method are reasonably well predicted in Damlica catchment when using both the topographic map and the GIS values, but overestimated for Kumdere and Vize catchments. Base time, $t_{b}$ values in SCS method are underestimated for all catchments. Peak discharge, $q_{p}$ values in DSI method are underestimated in Vize and Kumdere catchments but overestimated in Damlica catchment because of the shape factor. Base time, $t_{b}$ values in DSI method are underestimated for all catchments.

\section{References}

[1] V.T. Chow, D.R. Maidment, L.W. Mays, Applied Hydrology, McGraw-Hill Book Company, New York 1988.

[2] E. Todini, J. Hydrol. 100, 341 (1988).

[3] V. Mockus, in: SCS National Engineering Handbook, Section 4, Hydrology, Estimation of direct runoff from storm rainfall, Ch. 10, U.S. Dept. Agriculture, Washington 1972.

[4] L.F. Huggins, J.R. Burney, in: Hydrologic Modeling of Small Watersheds, Monograph 5, Ed. C.T. Haan, ASAE, Michigan 1982, p. 209 